Revista Bioética

\title{
PESQUISA
}

\section{Análise do preenchimento de declarações de óbito em Catanduva, São Paulo}

Cristhiana Kise Saito ${ }^{1}$, Ana Rafaela Foloni ${ }^{1}$, Caio Henrique Okuda de Oliveira ${ }^{1}$, Cibele Foloni Tessarolli ${ }^{1}$, Lívia Maria Borges da Silva ${ }^{1}$, Auro de Andrade Filho ${ }^{1}$

1. Centro Universitário Padre Albino, Araçatuba/SP, Brasil.

\section{Resumo}

A declaração de óbito é documento-base do Sistema de Informação sobre Mortalidade do Ministério da Saúde e abrange dados qualiquantitativos de cunho ético, jurídico e epidemiológico. Os registros do Ministério apresentam inconsistências provocadas por diversos fatores, principalmente relacionados à formação acadêmica dos profissionais e ao seu acesso às orientações de órgãos competentes. O objetivo deste trabalho foi identificar os principais erros no preenchimento das declarações de óbito registradas nos hospitais-escola de Catanduva/SP entre 2014 e 2017. Dos 805 documentos analisados, 167 (20,7\%) estavam incompletos; 59 (7,3\%) utilizavam termos inadequados; 42 (5,2\%) apresentavam siglas e abreviações; 27 (3,4\%) foram redigidos com caligrafia ilegível; e $2(0,2 \%)$ continham rasuras. Apesar da baixa frequência de erros, a análise demonstrou déficit no conhecimento e/ou descuido com a ética médica, o que compromete a qualidade dos registros de saúde pública.

Palavras-chave: Atestado de óbito. Saúde pública. Ética.

\section{Resumen}

\section{Análisis del Ilenado de las declaraciones de defunción en Catanduva, São Paulo, Brasil}

La declaración de defunción es un documento base del Sistema de Información sobre la Mortalidad del Ministerio de Salud, que incluye datos cualicuantitativos de carácter ético, legal y epidemiológico. Los registros del Ministerio presentan inconsistencias resultantes de diversos factores, sobre todo relacionados con la formación académica de los profesionales y con el acceso a las orientaciones de los órganos competentes. El objetivo de este trabajo fue identificar los principales errores en el llenado de las declaraciones de defunción registradas en los hospitales escuela de Catanduva, São Paulo, Brasil, en el período entre el 2014 y el 2017. De los 805 documentos analizados, 167 (20,7 \%) estaban incompletos; 59 (7,3\%) empleaban términos inadecuados; 42 (5,2 \%) presentaban siglas y abreviaturas; 27 (3,4\%) estaban escritos con una caligrafía ilegible; y 2 (0,2 \%) contenían tachones. A pesar de la baja frecuencia de errores, el análisis demostró un déficit en el conocimiento o negligencia en cuanto a la ética médica, lo que compromete la calidad de los registros de salud pública.

Palabras clave: Certificado de defunción. Salud pública. Ética.

\begin{abstract}
Analysis of the filling of death certificates in Catanduva, São Paulo, Brazil

The death certificate is the main document for the Mortality Information System of the Brazilian Ministry of Health, covering quantitative and qualitative aspects of ethical, legal and epidemiological nature. The records of the Ministry present inconsistencies caused by many factors, especially those related to poor academic training and access to guidelines published by entities. This study sought to identify the main errors in filling death certificates registered in a teaching hospital in Catanduva, São Paulo, Brazil, from 2014 to 2017. Of the 805 certificates, 167 (20.7\%) were incomplete, 59 (7.3\%) had inadequate terms, 42 (5.2\%) acronyms and abbreviations, 27 (3.3\%) illegible handwriting, and $2(0.2 \%)$ erasures. Despite the low frequency of errors, the analysis found deficits in knowledge and/or neglect of medical ethics, which compromise the quality of public health records.
\end{abstract}

Keywords: Death certificates. Public health. Ethics.

Aprovação CEP-Fameca CAAE 64641617.0.0000.5430

Declaram não haver conflito de interesse. 
A declaração de óbito é documento oficial de cunho ético, jurídico e epidemiológico, padronizado nacionalmente, e alimenta o Sistema de Informação sobre Mortalidade (SIM) do Ministério da Saúde ${ }^{1-4}$. Registra dados qualiquantitativos em três vias numeradas sequencialmente e que podem ser diferenciadas pela cor, de acordo com seu destino e sua função: de cor branca a ser encaminhada para a Secretaria Municipal da Saúde; de cor amarela para o representante da família do falecido, com o intuito de preservar o documento; e de cor rosa para ser arquivada no prontuário médico ${ }^{5}$.

Esse documento está associado a diversos prosseguimentos, haja vista as possíveis características do falecimento (causa natural, causa acidental e/ou violenta) ou do local onde ocorreu (instituições de saúde, via pública etc.) ${ }^{5}$. Trata-se de registro público que deve ser preenchido pelo médico e conter, entre outros dados, a identificação do falecido e as condições que levaram à sua morte, além de indicar se houve assistência médica ou não ${ }^{5,6}$.

É composto por nove blocos e 59 campos que correspondem a informações indispensáveis para atestar o falecimento do paciente: o bloco I, "Identificação", apresenta dados sociodemográficos do falecido e é acompanhado pelo bloco II, "Residência"; o bloco III, "Ocorrência", registra informações sobre o local de morte; o bloco IV, "Óbito fetal ou de menor de um ano", inclui, além de dados sobre o falecido, informações sobre sua mãe; o bloco V indica as "Condições e causas do óbito", abrangendo cronologia e causalidade dos eventos que desencadearam o falecimento; o bloco VI, "Médico", identifica o profissional que assina a declaração de óbito; o bloco VII, "Causas externas", indica a possibilidade de morte não natural; o bloco VIII, "Cartório", é preenchido exclusivamente pela repartição pública que o nomeia; e o bloco IX, "Localidade sem médico", indica a ausência desse profissional ${ }^{5,7}$.

O médico é responsável por averiguar e certificar o correto preenchimento da declaração de óbito, de forma que sejam registradas informações fidedignas do paciente, cumprindo dever ético e jurídico ${ }^{1}$. A necessidade de conferir a veracidade do documento relaciona-se a seu papel epidemiológico, desempenhado por meio da análise das principais particularidades populacionais dos óbitos ocorridos mais prevalentemente. Isso permite estabelecer o padrão de doenças de cada região, embasando ações estatais voltadas à promoção da saúde e prevenção de enfermidades, consolidadas pelas evidências fornecidas por pesquisas ${ }^{8,9}$.
Apesar do conhecimento amplamente disseminado sobre o valor do preenchimento correto da declaração de óbito, evidenciam-se registros insatisfatórios que causam inconsistência nos dados epidemiológicos coletados ${ }^{4}$. Essa fragilidade de informações pode ser justificada por diversos fatores, principalmente relacionados à formação acadêmica dos profissionais e ao acesso aos documentos informativos sobre o preenchimento adequado ${ }^{7}$.

No atual contexto da prática médica, a precariedade no levantamento estatístico traz delicado problema que afeta negativamente o avanço da ciência, visto que diversas pesquisas procuram indicar exatamente as principais causas e dúvidas envolvidas no mau preenchimento de atestados de óbito. Primordialmente, depreende-se desses estudos que muitos profissionais médicos desconhecem as reais implicações éticas, jurídicas e epidemiológicas do preenchimento indevido, incompleto ou ilegível da declaração de óbito. A informação atestada de forma deficiente se deve à negligência dos médicos quanto a dificuldades em aspectos básicos do documento, tal como a cronologia e a coerência dos eventos clínicos envolvidos na causa da morte, o preenchimento de óbitos fetais e maternos sem assistência e a indicação de causas externas em mortes violentas ${ }^{10,11}$.

É possível observar que a exigência de preenchimento adequado desse documento cumpre o objetivo de aprimorar os dados estatísticos sobre a morte da população, associado à melhoria do SIM. Com isso, este estudo tem por objetivo avaliar diversos critérios para o preenchimento íntegro e adequado da declaração de óbito, a fim de indicar erros relevantes e demonstrar falhas relacionadas à incompletude, que hipoteticamente sinalizam negligência dos profissionais de saúde e formação deficiente ${ }^{10}$.

\section{Materiais e método}

Trata-se de estudo observacional, descritivo, transversal e qualiquantitativo das declarações de óbito de pacientes falecidos entre 2014 e 2017 no Complexo de Hospitais-Escola Padre Albino e Emílio Carlos. Essas instituições são vinculadas ao Centro Universitário Padre Albino, sede do curso de medicina da cidade de Catanduva/SP, e atendem microrregião com 19 cidades e cerca de 200 mil habitantes, localizada no noroeste do estado de São Paulo. Os documentos analisados foram preenchidos por médicos vinculados a esses hospitais. 
Os dados das declarações de óbito originais foram colhidos e organizados em formulários (Anexo) para identificar e analisar os principais acertos e erros cometidos pelos médicos no seu preenchimento. Posteriormente, foram efetuados cálculos estatísticos e esses dados foram dispostos em gráficos, de acordo com cada bloco do documento, no intuito de compará-los por categoria e nível de complexidade do preenchimento.

As informações foram cedidas pelo arquivo do Hospital Emílio Carlos, onde as vias de cor rosa das declarações são armazenadas. Foram incluídos registros que apresentavam os blocos I, II, III, V e VI preenchidos, sendo excluídos da pesquisa dados relacionados a óbitos fetais e por causas externas. A seção VIII é preenchida exclusivamente pelo Cartório de Registro Civil, não envolvendo participação de médicos e, portanto, não foi considerada na análise. A pesquisa foi aprovada pelo Comitê de Ética em Pesquisa da Fundação Padre Albino e supervisionada pelos funcionários responsáveis pelo setor do arquivo.

Os blocos I (identificação), II (residência), III (local de ocorrência do óbito), V (condições e causas do óbito) e VI (dados do profissional) foram avaliados quanto a legibilidade, presença de rasuras e preenchimento completo de seus campos. O bloco $\mathrm{V}$ foi ainda avaliado quanto ao uso de termos inadequados ("falência de múltiplos órgãos", "parada cardiorrespiratória", "coma" e "causa desconhecida") e de abreviaturas e siglas não padronizadas.

Os pontos a serem observados no bloco $\mathrm{V}$ foram escolhidos com base em manuais de preenchimento de declaração de óbito. O livro Atestado médico: prática e ética ${ }^{12}$, publicado pelo Centro de Bioética do Conselho Regional de Medicina do Estado de São Paulo em 2013, considera os termos "falência múltipla de órgãos", "parada cardiorrespiratória" e "coma" inadequados por serem vagos e representarem consequências do processo de morte, não causas. O uso da expressão "causa desconhecida" também é desestimulado por esse manual por gerar atestado impreciso e omitir a causa-base do óbito, que deve ser ao menos questionada ${ }^{12}$.

Aconselha-se ainda evitar abreviaturas na confecção das declarações de óbito, de modo que o registro seja o mais claro possível, contribuindo para sua função epidemiológica ${ }^{12}$. Esse mesmo motivo fundamenta a exigência de que a caligrafia seja legível, termo que se refere a texto ou impresso que, por ser escrito em caracteres nítidos, bem visíveis e distintos, se pode ler com facilidade ${ }^{13}$. As caligrafias das declarações analisadas que ofereceram dificuldade de compreensão a mais de um dos cinco membros do grupo pesquisador foram classificadas como ilegíveis.

A rasura, entendida como eliminação de letra ou palavra de um texto escrito, riscando-as ou raspando-as ${ }^{14}$, também é estritamente proibida em qualquer documento médico. O Manual de instruções para o preenchimento da declaração de óbito da Fundação Nacional de Saúde ${ }^{11}$ frisa que o registro que contiver rasuras ou emendas deve ser anulado e encaminhado para o setor de processamento para controle.

\section{Resultados e discussão}

Das 805 declarações de óbito analisadas, $167(20,7 \%)$ estavam incompletas; 59 (7,3\%) continham termos inadequados; $42(5,2 \%)$, siglas e abreviações; 27 (3,4\%), caligrafia ilegível; e $2(0,2 \%)$, rasuras. A marcante frequência de registros incompletos nos arquivos dos hospitais pesquisados (Gráfico 1 ) indica provável falta de comprometimento, atenção ou capacitação do profissional responsável pelo seu preenchimento. Resultado semelhante foi obtido em outras análises, como o estudo realizado em Santa Catarina em 2014 com 528 declarações de óbito, das quais $50,18 \%$ estavam incompletas ${ }^{10}$.

Gráfico 1. Proporção de declarações de óbito completas e incompletas (Catanduva/SP, 2014-2017)

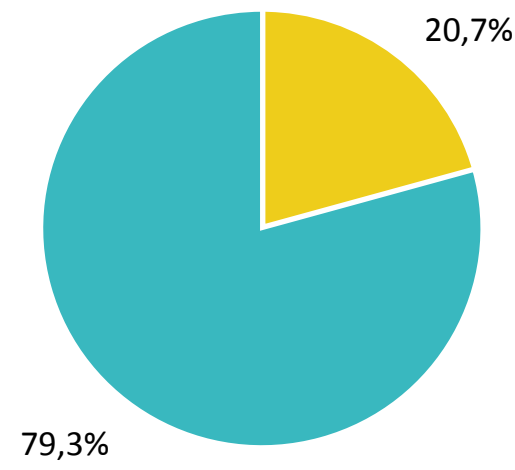

Incompletas Completas

A presença de siglas e abreviações, caligrafia ilegível e rasura aponta a permanência de vícios do cotidiano médico, o que pode prejudicar o entendimento e a análise das informações por profissionais de outras áreas. Fere ainda a responsabilidade ética do médico em seguir normas e padronizações estabelecidas para a composição de documento que cumpra função epidemiológica. 
Apesar da baixa incidência (7,3\%), ainda foram observados termos não recomendados por entidades reguladoras por serem imprecisos e vagos ${ }^{12}$. Esse achado corresponde à tendência nacional observada em estudo anterior, que detectou que, embora a proporção de óbitos por causas mal definidas tenha diminuído desde a década de 1980, sua frequência ainda foi estimada em $13 \%$ nos anos $2000^{15}$.

A análise das 59 declarações de óbito com termos inadequados constatou que $32(54,2 \%)$ indicavam "falência de múltiplos órgãos"; 21 (35,6\%), "causa desconhecida"; 3 (5,1\%), "parada cardiorrespiratória"; e 3 (5,1\%), "coma" (Gráfico 2).
Estudo de 2013 realizado em Belém/PA constatou uso mais frequente de termos vagos, totalizando $55 \%$ das declarações de óbito analisadas ${ }^{3}$.

Esse valor é consideravelmente superior ao encontrado nesta pesquisa, realizada no complexo hospitalar da Fundação Padre Albino, onde foram detectados menos erros de preenchimento, contrariando as expectativas iniciais dos pesquisadores. É possível que esse resultado seja reflexo de maior preparo e nível de instrução dos profissionais responsáveis por tais documentos médicos, que podem ter cursado disciplina sobre documentação médica na graduação.

Gráfico 2. Porcentagem de termos inadequados identificados nas declarações de óbito (Catanduva/SP, 2014-2017)

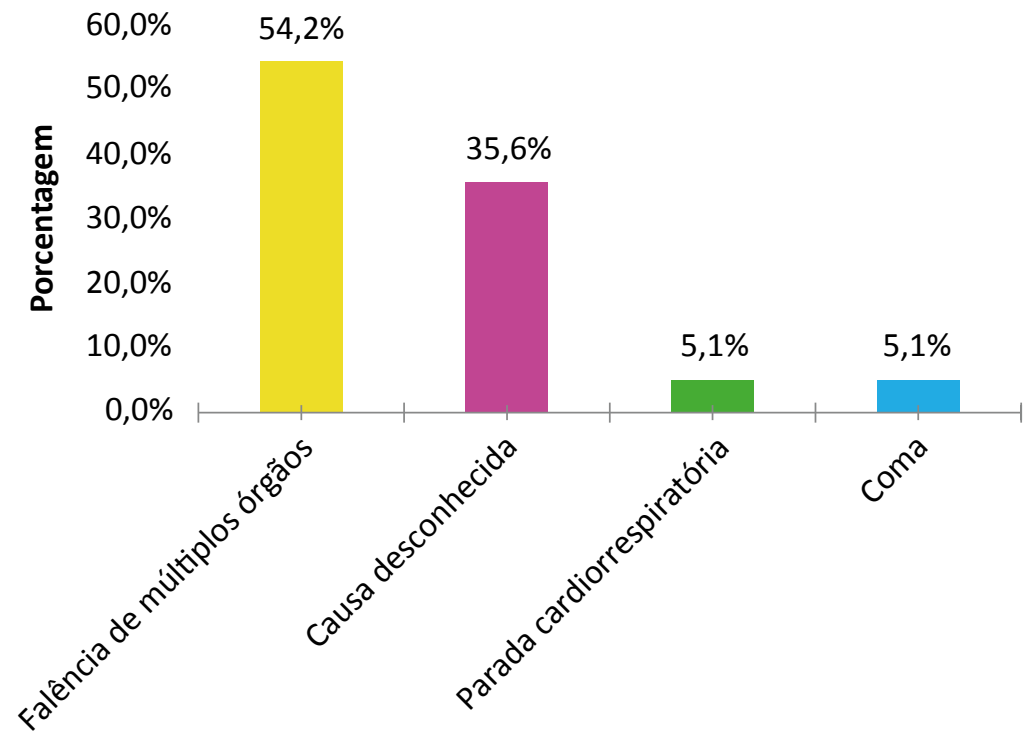

Termos inadequados

\section{Considerações finais}

A declaração de óbito é ato médico de relevância jurídica, ética e epidemiológica. Suas informações são computadas no SIM, que pode guiar o planejamento da área da saúde de acordo com dados de incidência e prevalência de cada doença, elucidando necessidades precípuas em campanhas de prevenção, abertura de novas unidades e financiamento de pesquisas e tratamentos.

É, portanto, imprescindível que as informações contidas neste documento sejam verdadeiras e específicas, sendo ainda direito de familiares receber dados corretos sobre a causa de morte do ente querido. Nesse contexto, comitês de investigação de óbito são indispensáveis, pois identificam as principais causas evitáveis de morte e propõem medidas para preveni-las, incitam discussões e instruem profissionais acerca do preenchimento adequado das declarações.

A partir dos resultados, este estudo mostra que ainda há déficit no saber médico acerca do preenchimento adequado das declarações de óbito e/ou descuido do profissional com a ética médica. Em vista disso, as instituições de ensino têm a obrigação de aprimorar os ensinamentos sobre o tema a fim de preparar os estudantes de forma satisfatória. Ademais, com o propósito de refinar o conhecimento de indivíduos já fora do ambiente acadêmico, pode-se investir em capacitações direcionadas à documentação médica. 


\section{Referências}

1. Brasil. Ministério da Saúde, Conselho Federal de Medicina, Centro Brasileiro de Classificação de Doenças. A declaração de óbito: documento necessário e importante [Internet]. 3a ed. Brasília: Ministério da Saúde; 2009 [acesso 2 jul 2018]. Disponível: https://bit.ly/367hNxk

2. Laurenti R, Jorge MHPM. O atestado de óbito: aspectos médicos, estatísticos, éticos e jurídicos [Internet]. São Paulo: Cremesp; 2015 [acesso 2 jul 2018]. Disponível: https://bit.ly/3exng4e

3. Silva JAC, Yamaki VN, Oliveira JPS, Teixeira RKC, Santos FAF, Hosoume VSN. Declaração de óbito, compromisso no preenchimento: avaliação em Belém - Pará, em 2010. Rev Assoc Méd Bras [Internet]. 2013 [acesso 20 set 2018];59(4):335-40. DOI: 10.1016/j.ramb.2013.03.001

4. Silva PHA, Lima ASD, Medeiros ACM, Bento BM, Silva RJS, Freire FD et al. Avaliação do conhecimento de médicos professores, residentes e estudantes de medicina acerca da declaração de óbito. Rev Bras Educ Méd [Internet]. 2016 [acesso 20 set 2018];40(2):183-8. DOI: 10.1590/1981-52712015v4 On2e01532014

5. Brasil. Ministério da Saúde. Manual de instruções para o preenchimento da declaração de óbito [Internet]. Brasília: Secretaria de Vigilância em Saúde; 2011 [acesso 20 set 2018]. Disponível: https://bit.ly/3eD1CLZ

6. Conselho Regional de Medicina do Estado do Rio Grande do Sul. Manual de atestado de óbito [Internet]. 2a ed. Porto Alegre: Cremers; 2018 [acesso 20 set 2018]. Disponível: https://bit.ly/315pB9f

7. Mendonça FM, Drumond E, Cardoso AMP. Problemas no preenchimento da declaração de óbito: estudo exploratório. Rev Bras Estud Popul [Internet]. 2010 [acesso 20 set 2018];27(2):285-95. DOI: 10.1590/S0102-30982010000200004

8. Santo AH. Potencial epidemiológico da utilização das causas múltiplas de morte por meio de suas menções nas declarações de óbito, Brasil, 2003. Rev Panam Salud Pública [Internet]. 2007 [acesso 20 set 2018];22(3):178-86. Disponível: https://bit.ly/2lfOqkm

9. Santo AH. Causas mal definidas de morte e óbitos sem assistência. Rev Assoc Méd Bras [Internet]. 2008 [acesso 20 set 2018];54(1):23-8. DOI: 10.1590/S0104-42302008000100016

10. Lucena L, Cagliari GHB, Tanaka J, Bonamigo EL. Declaração de óbito: preenchimento pelo corpo clínico de um hospital universitário. Rev. bioét. (Impr.) [Internet]. 2014 [acesso 20 set 2018];22(2):318-24. DOI: 10.1590/1983-80422014222013

11. Fundação Nacional de Saúde. Manual de instruções para o preenchimento da declaração de óbito [Internet]. Brasília: Funasa; 2001 [acesso 20 set 2018]. Disponível: https://bit.ly/3n2zrcC

12. Oselka G, coordenador. Atestado médico: prática e ética [Internet]. São Paulo: Conselho Regional de Medicina do Estado de São Paulo; 2013 [acesso 20 set 2018]. Disponível: https://bit.ly/32mX4o0

13. Michaelis: dicionário brasileiro da língua portuguesa [Internet]. São Paulo: Melhoramentos; 2015 [acesso 20 set 2018]. Legível. Disponível: https://bit.ly/2U42bFj

14. Michaelis: dicionário brasileiro da língua portuguesa [Internet]. São Paulo: Melhoramentos; 2015 [acesso 20 set 2018]. Rasura. Disponível: https://bit.ly/3p3eUGs

15. Jorge MHPM, Laurenti R, Gotlieb SLD. Análise da qualidade das estatísticas vitais brasileiras: a experiência de implantação do SIM e do Sinasc. Ciênc Saúde Coletiva [Internet]. 2007 [acesso 20 set 2018];12(3):643-54. DOI: 10.1590/S1413-81232007000300014

\section{Participação dos autores}

Os autores elaboraram este trabalho em conjunto.

\section{Correspondência}

Cristhiana Kise Saito - Rua Habib Rezek, 174, Aeroporto CEP 16052-900. Araçatuba/SP, Brasil.

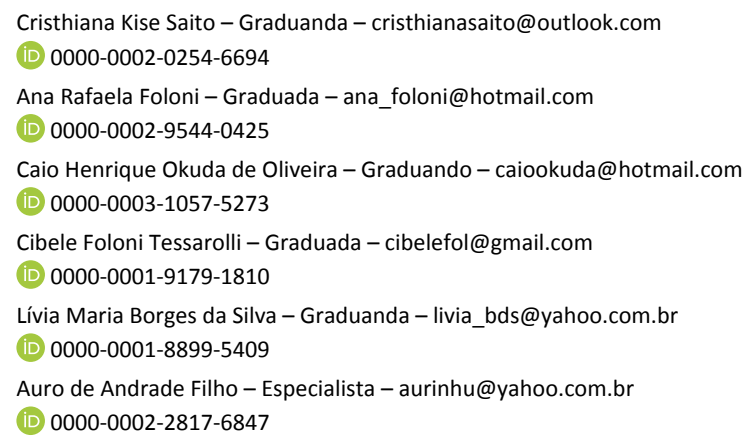




\section{Anexo}

\begin{tabular}{|c|c|c|c|c|c|}
\hline Preenchimento & Caligrafia & Rasuras & Siglas e abreviações & Termos inadequados & $\begin{array}{c}\text { Causas da morte } \\
\text { (bloco V) }\end{array}$ \\
\hline ( ) Completo & ( ) Legível & ( ) Presente & ( ) Presente & $\begin{array}{l}\text { ( ) Falência de } \\
\text { múltiplos órgãos }\end{array}$ & \\
\hline ( ) Incompleto & ( ) llegível & ( ) Ausente & ( ) Ausente & $\begin{array}{l}\text { ( ) Parada } \\
\text { cardiorrespiratória }\end{array}$ & \\
\hline \multirow[t]{2}{*}{ ( ) Em branco } & & & Local(is): & ( ) Coma & \\
\hline & & & & ( ) Causa desconhecida & \\
\hline
\end{tabular}

